\title{
Taxa de juros e mecanismos de transmissão da política monetária no Brasil*
}

\author{
RICARDO DE MENEZES BARBOZA**
}

\begin{abstract}
RESUMO: Este trabalho desenvolve a hipótese de que a taxa de juros brasileira é alta como resultado de mecanismos de transmissão monetária parcialmente obstruídos. Surgem falhas de transmissão devido às seguintes características da economia brasileira: (i) segmentação do mercado de crédito; (ii) baixa penetração do crédito livre dentro do processo de determinação de renda; (iii) truncada estrutura a termo da taxas de juros; (iv) a participação das LFT na composição da dívida pública; (v) a participação dos preços administrados no índice de preços ao consumidor. Para alcançar este resultado, o trabalho explora o modelo BMW e fornece algumas evidências preliminares.

PALAVRAS-CHAVE: Mecanismo de transmissão monetária; taxa de juro; política monetária.
\end{abstract}

ABSTRACT: Interest rate and monetary transmition mechanisms in Brazil. This paper develops the hypothesis that the Brazilian interest rate is high as a result of partially obstructed monetary transmission mechanisms. Transmission failures arise due to the following characteristics of the Brazilian economy: (i) segmentation of the credit market; (ii) low penetration of free credit within the income determination process; (iii) truncated term structure of interest rates; (iv) participation of LFTs in public debt; (v) participation of administered prices in the consumer price index. To achieve this result, the paper explores the BMW model and provides some preliminary evidence.

KEYWORDS: Monetary transmission mechanism; interest rate; monetary policy. JEL Classification: E40; E43; E52.

\section{INTRODUÇÃO}

Este artigo trata do problema da elevada taxa de juros no Brasil ${ }^{1}$. A hipótese

\footnotetext{
* O autor agradece aos comentários de Fernando Cardim de Carvalho, Antônio Luís Licha, Viviane Luporini e Lavínia Barros de Castro, isentando-os, por óbvio, de quaisquer erros remanescentes. As opiniões aqui expressas são pessoais e não refletem necessariamente a posição do BNDES.

** Banco Nacional do Desenvolvimento Social - BNDES. E-mail: ricardo.barboza@bndes.gov.br. Submetido: 28/Maio/2013: Aprovado: 14/Fevereiro/2014
} 
aqui desenvolvida coloca tal problema como uma implicação da existência de mecanismos de transmissão da política monetária parcialmente obstruídos.

As obstruções de transmissão decorreriam das seguintes características da economia brasileira: (i) segmentação no mercado de crédito, com alta participação do crédito direcionado; (ii) baixa penetração do crédito livre no processo de determinação da renda; (iii) truncada estrutura a termo da taxa de juros; (iv) participação de Letras Financeiras do Tesouro (LFTs) na composição da dívida pública, e; (v) participação de preços administrados na composição do índice oficial de inflação (IPCA).

Nesse contexto, a política monetária perde poder e um alto nível de taxa de juros passa a ser requerido para que o Banco Central possa minimamente cumprir com seu objetivo, que é manter a estabilidade de preços no país, com o produto operando ao nível do produto potencial. Este diagnóstico será construído com base em um modelo macroeconômico (simples) de três equações, o denominado modelo BMW, que contém uma Curva IS, uma Curva de Philips e uma Função de Perda do Banco Central.

Algumas evidências preliminares também são apresentadas. De fato, a taxa de juros no Brasil vem diminuindo pari passu à desobstrução de alguns mecanismos de transmissão e à elevação do poder da política monetária.

O artigo está organizado da seguinte forma. Além desta Introdução, a segunda seção faz uma revisão da literatura sobre a alta taxa de juros no Brasil. A terceira explora de forma teórica o tema dos mecanismos de transmissão da política monetária. A quarta apresenta as peculiaridades da economia brasileira que modificam e condicionam o modo pelo qual a política monetária opera no país. A quinta expõe o modelo BMW, que possibilita a conexão entre obstruções de transmissão e nível da taxa de juros. A sexta apresenta algumas evidências preliminares sobre a hipótese deste trabalho. Por fim, são feitas algumas considerações finais.

\section{LITERATURA SOBRE TAXA DE JUROS NO BRASIL}

Por que é tão elevada a taxa de juros no Brasil? Diferentes explicações podem ser encontradas na literatura sobre o tema.

Favero e Giavazzi (2002) argumentam que a taxa de juros é alta devido ao alto nível da dívida pública. Todavia, as evidências empíricas disponíveis não corroboram esta hipótese. Muinhos e Nakane (2006), por exemplo, não encontram evidência de uma relação positiva entre nível da dívida pública e taxa de juros real. De fato, um

\footnotetext{
${ }^{1}$ Segundo Franco (2006, p. 277), a compreensão deste problema representa “o maior desafio intelectual e prático da profissão desde o fim da hiperinflação". De fato, o Brasil é uma anomalia em termos de taxa de juros real. Em dezembro de 2013, o Brasil ocupava a liderança em ranking internacional de taxa real ex-ante $(4,1 \%$, contra $3,1 \%$ da China e $2,8 \%$ do Chile, respectivamente, segundo e terceiro colocados).
} 
simples exame da tendência da dívida pública bruta e da taxa real de juros (Gráfico 1) mostra que não há uma aparente relação positiva entre tais variáveis².

\section{Grafico 1: Taxa Real de Juros e Dívida Pública Bruta/PIB}

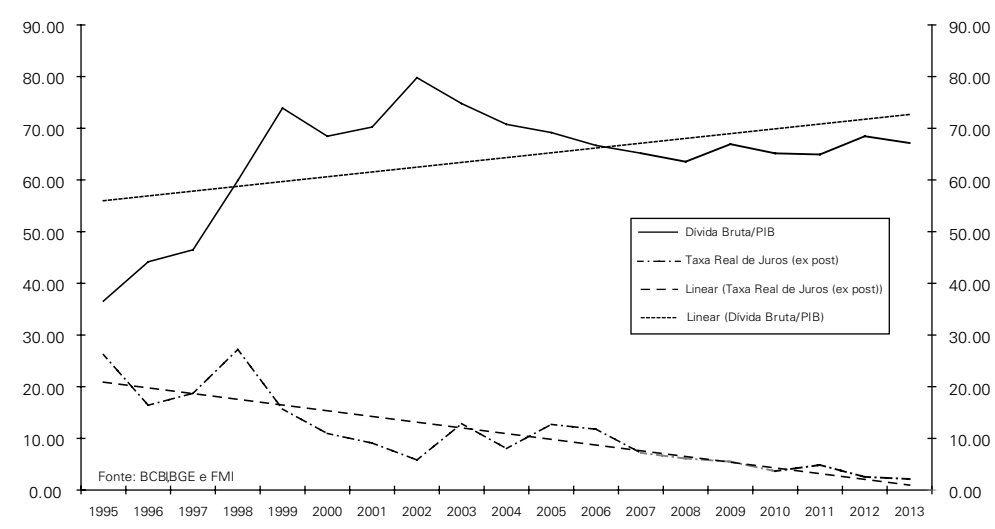

Arida, Bacha e Resende (2004) apontam a conjectura de incerteza jurisdicional como explicação para o problema da taxa de juros no Brasil ${ }^{3}$. No entanto, Gonçalves, Holland e Spacov (2007), através de um painel com dados de 50 países, rejeitam a validade empírica desta hipótese. Nas palavras dos autores, “[...] results reject Arida, Bacha e Resende's conjecture and its variants, showing that jurisdictional uncertainty [...] cannot satisfactorily explain the short-term real interest rate" (Ibidem; p. 68). O próprio Resende (2011), um dos formuladores desta tese, admite que algumas tentativas de encontrar evidência para esta formulação foram realizadas, mas sem sucesso.

Erber (2008) coloca a elevada taxa de juros como o resultado de uma influente coalizão de interesses formada em torno da manutenção dos juros em niveis elevados. Esta coalizão seria benéfica tanto para rentistas - que lucram com aplicações financeiras - quanto para o Banco Central do Brasil (BCB), que se beneficia da reputação de ser um banco central conservador. Entretanto, não há qualquer evidência de que as taxas de juros no Brasil tenham sido exageradas, pelo menos desde a introdução do Regime de Metas de Inflação. Fosse este o caso, teríamos que observar a inflação sistematicamente abaixo da meta, mas, como pode ser visto no Gráfico 2, isto está longe de ser verdade.

Arida (2003a) argumenta ser a alta taxa de juros decorrência da ausência de conversibilidade plena da moeda nacional. Porém, fosse esta tese verdade, outros países emergentes sem conversibilidade plena também deveriam apresentar taxas de

\footnotetext{
${ }^{2}$ Embora essa seja apenas uma relação entre duas variáveis, a inclusão da dívida pública bruta em uma regressão em painel não produz resultados robustos, e em algumas especificações o efeito aparece com sinal inverso ao esperado - ver, a esse respeito, Segura-Ubiergo (2012).

${ }^{3} \mathrm{O}$ termo incerteza jurisdicional designa uma incerteza de caráter difuso e de difícil mensuração que incide sobre a estabilidade e a segurança dos contratos firmados sob determinada jurisdição.
} 
juros semelhantes à brasileira, o que não é o caso. Além disso, o argumento de que a inconversibilidade aumenta as taxas de juros, devido ao seu efeito sobre o prêmio de risco - país, está longe de constituir um consenso empírico — ver Ono et al. (2005).

Gráfico 2: Desvios da Inflação Efetiva em Relação à Meta de Inflação

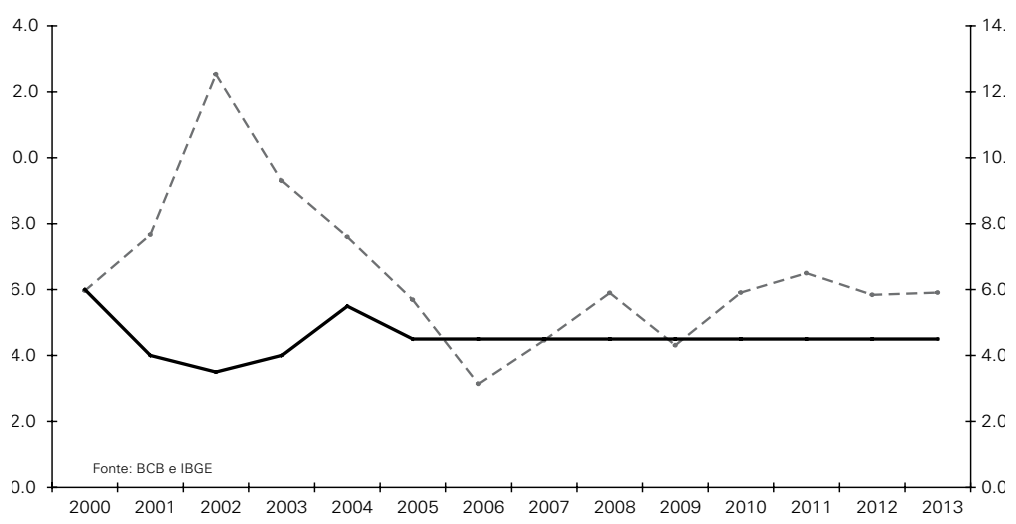

Barros (2011) aponta a elevada taxa de impaciência do brasileiro como possível causa da alta taxa de juros. Apenas taxas exorbitantes de juros seriam capazes de fazer o cidadão brasileiro médio adiar o consumo presente 4 . Esta explicação, contudo, apenas introduz novos problemas à discussão, tal como coloca Schwartsman (2011). Em primeiro lugar, qual seria a origem desta elevada impaciência? E por que motivo ela atingiria somente brasileiros e não, por exemplo, colombianos ou vietnamitas? ${ }^{5}$

Bresser e Nakano (2002) afirmam que a taxa de juros no Brasil é elevada devido ao fato dela se prestar a atingir objetivos múltiplos: (i) reduzir a demanda para controlar a inflação; (ii) limitar a desvalorização cambial para evitar inflação de custos; (iii) atrair capital externo para fechar o balanço de pagamentos; (iv) induzir investidores a comprar títulos para financiar a dívida pública; (v) reduzir o déficit comercial através do controle da demanda interna. Entretanto, algumas destas funções, embora realidade à época de câmbio administrado no país, deixaram de governar a dinâmica da taxa de juros sob o regime de metas de inflação. Sob este, o objetivo único da taxa de juros é manter a taxa de inflação em uma meta pre-estabelecida.

Oreiro e Paula (2011) afirmam que a razão fundamental de um juro tão elevado deve-se ao fato de o Brasil ser o único país no mundo onde o mercado mone-

\footnotetext{
${ }^{4}$ Importante salientar que o próprio Barros (2011) questiona a validade desta tese. No entanto, como se trata de um argumento um tanto comum neste debate, merece ser mencionado.

${ }^{5}$ A rigor, a própria natureza do argumento de que a taxa de juros constitui o prêmio pelo adiamento do consumo presente é discutível. Com efeito, no debate que opôs Keynes a Ohlin e Robertson pós-teoria Geral, Keynes defendeu sua posição de que a taxa de juros é a recompensa por se abrir mão da liquidez — isto é, o preço que guia a escolha entre forma líquida e ilíquida de riqueza, ao invés da escolha entre consumo presente e consumo futuro como concebida pela teoria clássica. Para maiores detalhes, ver Keynes (1937a, 1937b e 1937c), Ohlin (1937a, 1937b) e Robertson (1937).
} 
tário e o mercado de dívida pública estão umbilicalmente conectados, por intermédio das Letras Financeiras do Tesouro. Nesse contexto, a taxa Selic é obrigada a cumprir duas funções: ela é a taxa que regula os empréstimos no mercado interbancário ao mesmo tempo em que é a taxa pela qual o Tesouro rola parte significativa da dívida. Assim, a fragilidade ainda remanescente das contas públicas brasileiras acaba por fazer com que a taxa de juros requerida pelo mercado para rolagem da dívida pública seja excessivamente alta. Ou seja, a função de rolagem da dívida pública acaba contaminando a função de instrumento de política monetária $^{6}$. Esta hipótese, no entanto, ainda carece de maiores evidências, pois se a função de rolagem da dívida pública estivesse realmente contaminando a função de instrumento de política monetária (prendendo-a em patamares elevados), então deveríamos observar uma taxa de juros acima do que seria necessário para fins de cumprimento da meta de inflação. Mas, como visto no Gráfico 2, não é isso que ocorre no caso da economia brasileira ${ }^{7}$.

Arida (2003b) argumenta que a alta taxa de juros no Brasil pode ser decorrência de um problema de equilíbrios múltiplos. Entretanto, a recomendação de política econômica decorrente dessa hipótese traz riscos que dificilmente alguma autoridade monetária aceitaria correr, uma vez que não há comprovação empírica da validade desta hipótese. Não existe certeza de que, na hipótese de efetivamente existir um melhor equilíbrio, dado que estamos no "mau equilíbrio", fosse possível atingi-lo pela mera redução, brusca ou gradual, da taxa de juros. Em outras palavras, o entorno do equilíbrio perverso pode ser instável e não garantir a convergência para o melhor equilíbrio ${ }^{8}$.

Antes de prosseguir, uma advertência. Todas as diversas teses supracitadas, e ainda há muitas mais ${ }^{9}$, merecem ser examinadas enquanto objetos específicos de análise. A discussão aqui realizada teve apenas a intenção de ilustrar a complexidade do debate e introduzir o cenário no qual se insere a hipótese deste trabalho, qual seja, a de que a alta taxa de juros no Brasil decorre, pelo menos em parte, da

\footnotetext{
${ }^{6}$ A tese de Oreiro e Paula (2011) pode ser vista como um aprofundamento da tese de objetivos múltiplos de Bresser e Nakano (2002) no tocante à função (iv) da taxa de juros, de induzir investidores a comprar títulos para financiar a dívida pública.

${ }^{7}$ Barbosa (2006) formaliza um argumento um pouco diferente de contágio das LFTs na taxa real de juros, que passa pela inclinação da estrutura a termo da taxa de juros, o que inclui a taxa de juros controlada pela autoridade monetária. Nas palavras do autor, "the contagion effect of public debt on monetary policy will be defined as the risk premium built into the nominal rate of interest of Central Bank" (p. 232).

${ }^{8}$ Ver Mesquita (2014) para uma argumentação contrária a tese de equilíbrios múltiplos, com base na experiência brasileira para o período 2011-2013.

${ }^{9}$ Uma tese também bastante comum afirma que a alta taxa de juros no Brasil resulta da alta inflação de serviços, que é um setor com menor elasticidade da oferta. Todavia, como mostra Baumol (2012), a inflação mais elevada de serviços é um fenômeno que se aplica mundialmente. Nos EUA, por exemplo, há 50 anos que a inflação de serviços tem sido mais elevada do que o CPI cheio. Por ser um fenômeno internacional e pelo fato dos países conseguirem lidar com ele com juros menores, reforça-se a percepção de que o alto patamar vigente de juros no Brasil se deve a fatores internos, tal como será argumentado pela hipótese desenvolvida por este artigo (mecanismos de transmissão parcialmente obstruídos).
} 
existência de mecanismos de transmissão da política monetária parcialmente obstruídos. Vamos, no entanto, passo a passo, começando pelo tema dos mecanismos de transmissão da política monetária.

\section{MECANISMOS DE TRANSMISSÃO DA POLÍTICA MONETÁRIA}

Os mecanismos de transmissão da política monetária são os elos que conectam instrumento e objetivo da política monetária. A compreensão destes elos, contudo, está longe de ser uma questão trivial.

A cauda chacoalha o cachorro. Ao mover delicadamente uma pequena cauda, [a autoridade monetária] chacoalha um cachorro enorme, a grande economia americana. Isto não é notável? [...] Porque a política monetária funciona? Como? É um mistério que não é plenamente compreendido nem pelos banqueiros centrais nem pelos economistas. (Tobin, 2003, p. 171).

Na definição de Taylor (1995, p. 11): "the monetary transmission mechanism [is] the process through which monetary policy decisions are transmitted into changes in real GDP and inflation". São cinco os principais mecanismos de transmissão da política monetária ${ }^{10}$ : (i) canal do crédito; (ii) canal do valor de ativos; (iii) canal do câmbio; (iv) canal das taxas de juros; (v) canal das expectativas inflacionárias. A seguir, estes diversos canais são apresentados, ceteris paribus e sob um ponto de vista teórico.

\section{Canal do Crédito}

O canal do crédito transmite os impulsos de política monetária em direção à economia real via alterações no preço do crédito. Este movimento ocorre porque uma alteração na taxa de juros básica (i) pode ser rapidamente transmitida às taxas de juros prevalecentes no mercado de crédito ( $i$ 's ${ }_{\text {operaçöes de crédito }}$ ). Com taxas mais elevadas, as famílias resistem à contratação de dívidas, o que pode impactar negativamente no consumo agregado $(C)$, e as empresas tornam-se mais relutantes em iniciar novos projetos de investimento (I) em resposta a custos de financiamentos mais elevados e a perspectivas de recuo no consumo das famílias ${ }^{11}$ :

\footnotetext{
${ }^{10}$ Para os quatro primeiros canais, ver Mishkin (1995). Para o canal das expectativas inflacionárias, ver, dentre outros, Ball (1992), Bomfim et al. (1997) e Roberts (2006).

${ }^{11}$ Segundo Bernanke e Gertler (1995), o canal do crédito pode ser subdividido em dois componentes desde que se perceba que mercados de crédito são particularmente afetados pelo problema de informação assimétrica: bank lending channel e o balance sheet channel. O primeiro entende que a maioria dos tomadores de crédito, em especial empresas pequenas, não tem acesso ao mercado de capitais (só obtém crédito quando os bancos colocam à sua disposição). O segundo percebe o valor das ações das empresas
} 


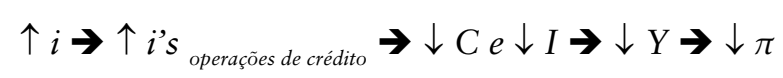

\section{Canal do Valor de Ativos}

O canal do valor de ativos afeta o comportamento de consumidores via efeito riqueza. Este efeito pode ser entendido como o impacto de variações da taxa de juros (i) sobre a riqueza financeira dos agentes (W). Ele ocorre porque o preço de um ativo $(P A)$ reflete fundamentalmente o valor presente esperado do fluxo de caixa que esse ativo deve proporcionar ao investidor. Um aperto monetário, ao elevar as taxas de desconto que trazem o fluxo ao seu valor presente, deprime o preço do ativo e, assim, empobrece seu detentor. Esse empobrecimento, por sua vez, diminui a demanda do investidor por bens e serviços:

$$
\uparrow i \rightarrow \downarrow P A \rightarrow \downarrow W \rightarrow \downarrow C \rightarrow \downarrow Y \rightarrow \downarrow \pi
$$

Além do efeito riqueza direto sobre o consumo, o canal do valor de ativos também conecta a política monetária à economia real por meio de modificações no balanço de instituições financeiras, em particular bancos comerciais. Como estas instituições são tipicamente grandes detentoras de dívida pública e também de equities, elas sofrem perdas (ganhos) quando a taxa de juros se eleva (reduz). As perdas financeiras, por sua vez, tornam os bancos mais cautelosos em suas políticas de crédito, com impactos sobre o volume concedido de empréstimos:

$$
\uparrow i \rightarrow \downarrow P A \rightarrow \downarrow \text { Crédito } \rightarrow \downarrow C e \downarrow I \rightarrow \downarrow Y \rightarrow \downarrow \pi
$$

\section{Canal do Câmbio}

O canal da taxa de câmbio mostra-se especialmente importante em economias mais abertas, com taxa de câmbio flutuante e livre movimentação de capitais, transmitindo os impulsos monetários adiante de duas maneiras distintas: via alterações nas exportações líquidas e via alterações nos preços dos bens comercializáveis internacionalmente (os chamados "tradables").

As alterações nas exportações líquidas ocorrem, pois a partir de um movimento na taxa básica de juros $(i)$, tudo o mais constante, o diferencial internacional de juros se altera na mesma proporção, alterando também as oportunidades de ganho em ativos domésticos. A movimentação internacional de capitais, estimulada pelo diferencial de juros, tende a rebater na taxa nominal de câmbio $(e)$ e, ao menos no curto prazo, na taxa real de câmbio $(\theta)$, importante determinante das exportações líquidas de um país (NX). De acordo com Taylor (1995, p. 17) “[...] the inverse relationship between the exchange rate and net exports is one of the more robust in empirical economics":

$$
\uparrow i \rightarrow \downarrow e \rightarrow \downarrow \theta \rightarrow \downarrow N X \rightarrow \downarrow Y \rightarrow \downarrow \pi
$$

como sensível à política monetária, de modo que, quando, por exemplo, a taxa de juros sobe, o valor das firmas se reduz, se elevando a possibilidade de seleção adversa e risco moral no mercado de crédito. 
As alterações nos preços dos tradables, por sua vez, têm influência direta na dinâmica da taxa de inflação. Este impacto ocorre porque elevações na taxa de juros (i) tendem a apreciar a taxa de câmbio nominal $(e)$, tornando mais baratos os preços em moeda doméstica de bens e serviços importados, tanto finais quanto intermediários utilizados em processos produtivos locais:

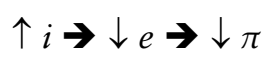

\section{Canal das Taxas de Juros}

A consideração do canal das taxas de juros passa pela suposição de existência de uma estrutura a termo da taxa de juros (ou curva de rendimentos) bem definida. Em condições de normalidade, se existir na realidade uma relação definida, qualquer que seja sua causa, entre taxas de juros de diferentes maturidades, o banco central terá o poder de alterar todo o complexo de taxas de juros da economia através unicamente de uma alteração na taxa de curtíssimo prazo (intercepto da estrutura a termo). Considerando que as taxas longas de juros ( $i$ 's longas $_{\text {as }}$ ) salternativas à eficiência marginal do capital, o investimento agregado $(I)$ pode se alterar pari passu aos movimentos de política monetária.

$$
\uparrow i \rightarrow \uparrow i_{\text {longas }} \rightarrow \downarrow I \rightarrow \downarrow Y \rightarrow \downarrow \pi
$$

Pelo lado do consumo $(C)$, tomando-se como variável exógena as preferências intertemporais de consumo dos agentes, uma alteração das taxas de juros modifica as escolhas intertemporais de consumo e poupança, porque maiores (menores) taxas de juros elevam (reduzem) o custo de oportunidade do consumo presente:

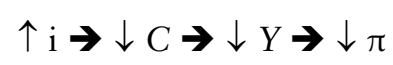

\section{Canal das Expectativas Inflacionárias}

As expectativas de inflação possuem papel importante na determinação da dinâmica inflacionária $(\pi)$ e costumam responder negativamente a alterações na taxa básica de juros. Com efeito, as expectativas de inflação atuam sobre o processo de formação de preços de três formas distintas: (i) diretamente, por intermédio de sua incorporação aos preços de produtos e serviços; (ii) via salários, pela sua incorporação aos salários nominais em negociação $(w)$, que representam importante item de custo para as empresas; (iii) indiretamente, porque alteram a taxa real de juros ex-ante $\left(\mathrm{r}_{\text {ex-ante }}\right)$ :

$$
\uparrow i\left\{\begin{array}{l}
\rightarrow \downarrow \pi^{e} \rightarrow \downarrow \pi \\
\rightarrow \downarrow \pi^{e} \rightarrow \downarrow w \rightarrow \downarrow \pi \\
\rightarrow \downarrow \pi^{e} \rightarrow \uparrow r_{\text {ex-ante }} \rightarrow \downarrow C \downarrow I \rightarrow \downarrow Y \rightarrow \downarrow \pi
\end{array}\right.
$$

A figura, a seguir, representa uma síntese dos mecanismos de transmissão da política monetária que foram discutidos até aqui: 
Figura 1 - Síntese dos Mecanismos de Transmissão da Politica Monetária

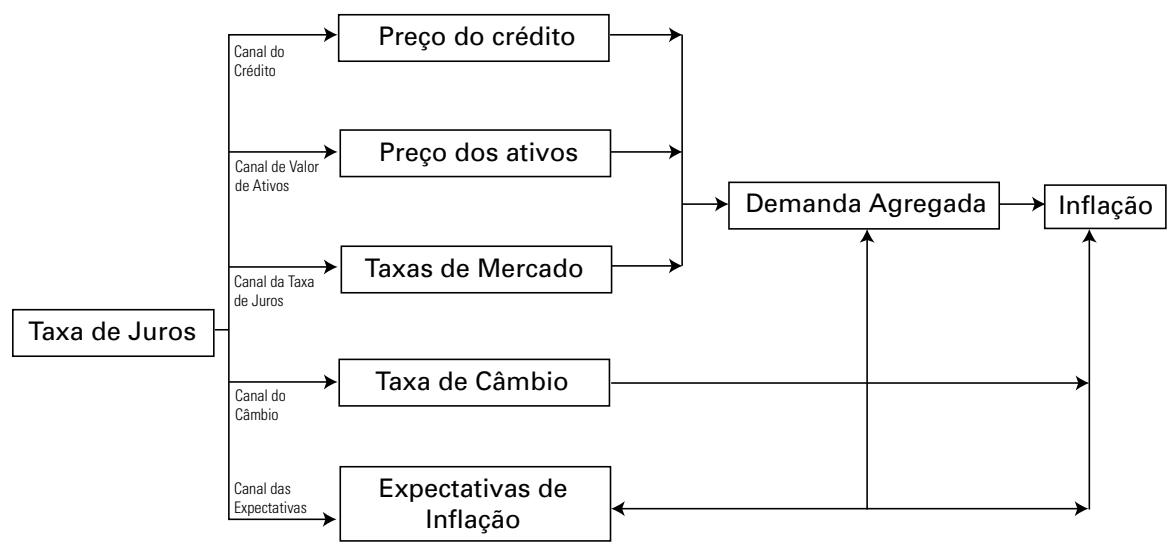

\section{MECANISMOS DE TRANSMISSÃO DA POLÍTICA MONETÁRIA NO BRASIL}

Saindo do plano teórico em direção à realidade da economia brasileira, percebe-se que a última apresenta uma série de peculiaridades que modificam e condicionam o modo pelo qual a política monetária opera no país. Isto ocorre, pois diversos mecanismos de transmissão encontram-se obstruidos, em graus diferentes, no Brasil. As obstruções de transmissão decorrem das seguintes características da economia brasileira: (i) segmentação no mercado de crédito, com alta participação do crédito direcionado; (ii) baixa penetração do crédito livre no processo de determinação da renda; (iii); participação de LFT’s na composição da dívida pública; (iv) truncada estrutura a termo da taxa de juros, e; (v) participação de preços administrados na composição do IPCA.

\section{Segmentação no mercado de crédito}

A existência de um mercado de crédito significativamente segmentado, onde parcela importante dos empréstimos não é afetada pela taxa em que o banco central realiza a política monetária, torna o mecanismo de transmissão do crédito parcialmente obstruído no Brasil — Pastore (2006), Bacha (2011) e Schwartsman (2011).

As operações de crédito do Sistema Financeiro Brasileiro (SFB) dividem-se em dois grandes segmentos: (i) segmento do crédito livre; (ii) segmento do crédito direcionado. A singularidade do SFB não está na existência, mas na significância da parcela do crédito direcionado (cerca de $40 \%$ do crédito total, em 2013), cujas operações englobam BNDES, crédito habitacional e crédito rural:

[...] a oferta de crédito de longo prazo no Brasil [...] é feita majoritariamente na forma de créditos direcionados, sob a liderança de três grandes públicos federais. O crédito para investimentos das empresas é realizado, em grande parte, por meio de operações do BNDES. Os fi- 
nanciamentos habitacionais são, em grande parte, concedidos no âmbito do Sistema Financeiro da Habitação, sendo a principal instituição financiadora a Caixa Econômica Federal, e o crédito rural é especialidade do Sistema Nacional de Crédito Rural, que tem o Banco de Brasil como principal agente financiador. (Lundberg, 2011, p. 4)

O segmento do crédito direcionado se distingue do segmento do crédito livre, dentre outros fatores, por dois grandes motivos. Primeiro, o preço que baliza suas operações não é sensível às alterações da política monetária. Desse modo, "boa parte do crédito no Brasil independe das decisões do Banco Central" (Bacha, 2011, p. 137). Segundo, seu preço é tipicamente inferior à taxa básica de juros. Assim, de acordo com Schwartsman (2011), "o nivel da Selic afeta menos a demanda agregada privada doméstica do que faria na ausência do crédito direcionado" ${ }^{12}$.

Isto posto, quanto maior a participação do crédito direcionado no crédito total, menor deve ser a capacidade da política monetária de afetar a evolução da demanda agregada e, consequentemente, da taxa de inflação ${ }^{13}$.

O esquema abaixo ilustra essa obstrução de transmissão, que impede a taxa de política monetária de afetar todas as taxas do mercado de crédito no Brasil:

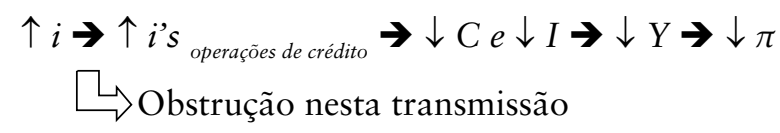

\section{Baixa penetração do crédito livre na determinação da renda}

Mesmo sendo o único segmento do crédito responsável por transmitir adiante os impulsos de política monetária no Brasil, o crédito livre é pouco representativo para fins de determinação da demanda agregada (relação Crédito Livre/PIB de cerca de 30\%, em 2013). Diante disso, deve ser pouco expressivo o efeito da transmissão monetária pela única via do canal do crédito que funciona na economia brasileira.

Ainda na implementação do regime de metas de inflação no país, Bogdanski, Tombini e Werlang (2000, p. 14) foram enfáticos ao se referirem a pouca expressividade do canal do crédito:

\footnotetext{
${ }^{12}$ De fato, não há como negar o comportamento peculiar da demanda privada doméstica no Brasil: a evidência sugere que mesmo altas taxas reais de juros, que provocariam recessões bíblicas em qualquer outra economia do planeta, parecem aqui consistentes com forte expansão da demanda.

${ }^{13}$ Nesse sentido, é possível que o aumento de participação do crédito direcionado no pós-2009 tenha contribuído para obstruir ainda mais o mecanismo de transmissão do crédito e elevar o nível de equilíbrio da taxa de juros. Para visualizar esta proposição, suponha uma curva IS, cuja taxa de juros seja uma média (ponderada pelas participações dos créditos livre e direcionado no crédito total) entre Selic e TJLP, tal como: $y=a-b r ; ~ r=\alpha($ Selic $)+(1-\alpha)$ (TJLP). Quanto maior a participação do crédito direcionado e/ou menor o nível da TJLP, maior será o nível de taxa Selic requerido pelo BCB para manter a estabilidade de preços no país. Para maiores detalhes da relação entre obstruções de transmissão e nível de juros, ver a quinta seção.
} 
[...] given historical low leverage of the Brazilian corporate sector along with the very strict credit and monetary policies implemented with the Real plan, the credit mechanism has not operated and its importance in terms of channeling interest rate impacts on inflation has been negligible.

Segundo Cardim de Carvalho et al. (2007), a atrofia do crédito livre no país pode ser explicada por dois motivos: (i) décadas de inflação elevada forçaram o sistema bancário a cobrar taxas de juros excessivamente elevadas, o que acabou reduzindo a oferta de crédito na economia; (ii) anos de desequilíbrios fiscais cederam um bom e rentável destino para os recursos bancários, alternativos à concessão de crédito ao setor privado. Assim, "apesar de a literatura internacional dar atenção especial ao canal de crédito no estudo dos mecanismos de transmissão da política monetária, no caso brasileiro o canal de crédito desempenha papel secundário" (Mendonça, 2001, p. 71).

Todavia, a relação crédito livre/PIB no Brasil muito se elevou nos últimos anos - passou de $14 \%$ para cerca de $30 \%$, entre 2000 e 2013. Mas a despeito deste movimento, o grau de aprofundamento do crédito ainda permanece em níveis relativamente baixos no Brasil — veja Sant'anna, Borça Junior e Araújo (2009) ${ }^{14}$. Nesse cenário, os impactos das alterações da taxa de juros devem mobilizar apenas uma pequena parcela da demanda agregada. Portanto, espera-se pouca expressividade para os efeitos da transmissão monetária através do canal do crédito livre na economia brasileira:

$$
\begin{aligned}
\uparrow i \rightarrow \uparrow \text { 's }_{\text {operaçōes de crédito livre }} & \rightarrow \downarrow C e \downarrow I \rightarrow \downarrow Y \rightarrow \downarrow \pi \\
& \square \text { Pouca expressividade nesta transmissão }
\end{aligned}
$$

\section{Participação de LFTs na composição da dívida pública federal}

A transmissão da política monetária pelo canal do valor de ativos no Brasil tem seus efeitos enfraquecidos devido à expressiva participação de títulos pós-fixados e sem risco de taxa de juros (LFTs) na composição da dívida pública federal (cerca de 20\% em 2013, mas que já chegou a ser mais de 60\% em 2003) - ver, dentre outros, Pastore (1996, 2006), Oreiro e Amaral (2008), Franco (2006) e Andrade e Castro Pires (2009).

As LFTs constituem um tipo bem peculiar de papel porque possuem duração zero, isto é, elasticidade nula de seu preço em relação à taxa de juros:

[...] as LFTs são a sistematização de um processo, [...] um título exatamente equivalente a uma aplicação de um dia feita repetidamente.

\footnotetext{
${ }^{14}$ Uma questão importante que surge dessa constatação (e que precisa ser ainda quantificada em trabalho específico) é a diferença entre nível e taxa de crescimento do crédito: se por um lado um maior crescimento aumenta poder da política monetária, por outro, causa algumas pressões de curto prazo que demandam ajustes de política monetária por parte do BCB (com impacto no nível da taxa de juros).
} 
É uma espécie de economia processual em se aplicar no overnight [...] uma forma de "securitização" do investimento no overnight. Por isso se diz que as LFTs funcionam como uma espécie de depósito à vista remunerado diariamente no $\mathrm{BC}$, ou como uma quase moeda que rende juros, e sem risco de juros, em razão da periodicidade de sua remuneração. Pode-se dizer, portanto, que a LFT tem duração zero. (Franco, 2006, p. 273, grifos do original)

Ao contrário do que ocorre com títulos prefixados, em que aumentos da taxa de juros diminuem o preço de mercado do título e, portanto, tornam os detentores de tais ativos mais pobres, no caso das LFTs esse mecanismo não existe. A imunidade ao efeito riqueza é, portanto, uma característica marcante das LFTs. O aumento da taxa de política monetária, ao mesmo tempo em que eleva os fatores de desconto aplicados aos rendimentos das LFTs, aumenta estes rendimentos exatamente na mesma proporção, eliminando assim o impacto sobre o preço do título e sobre a riqueza do detentor.

Se no caso das LFTs o efeito riqueza não opera, então somente a outra parte da dívida pública no Brasil é que transmite a política monetária de forma "correta", o que caracteriza uma clara obstrução no canal de transmissão do valor de ativos ${ }^{15}$ :

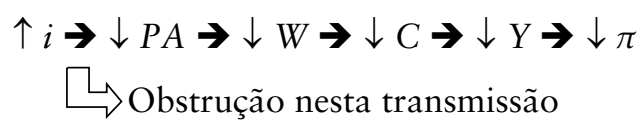

Ademais, como bancos comerciais no Brasil costumam aplicar parte de seus ativos em LFTs ${ }^{16}$, então parcela importante dos ativos bancários permanece imune a variações de taxa de juros, devido à duration zero daqueles papéis. Nesse cenário, a política monetária pelo canal do valor de ativos tende a perder força, pois bancos deixam de contrair o crédito na mesma magnitude que o fariam na ausência de LFTs:

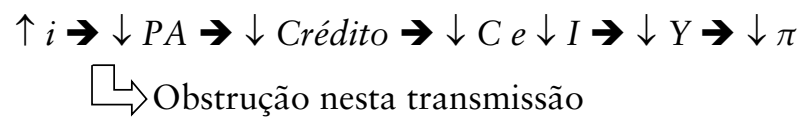

Loyo (2006) contesta a visão acima. Para este autor, o mecanismo de transmissão do valor de ativos não tem a importância quantitativa tão firmemente estabelecida quanto parece presumir sua discussão no Brasil. Os motivos da sua baixa importância seriam: (i) movimentos na riqueza induzidos pela política monetária são iminentemente temporários, logo têm impacto reduzido sobre o consumo dos agentes $^{17}$; (ii) mesmo um efeito riqueza supostamente identificado com choques monetá-

\footnotetext{
${ }^{15}$ Pastore $(1996,2006)$ levanta a possibilidade teórica das LFTs trazerem um "efeito transferência”, no caso dos agentes consumirem a partir da renda disponível.

${ }^{16}$ Ver Franco (2006) para a demanda bancária por um ativo sem risco de taxa de juros, como as LFTs.

${ }^{17}$ Ludvigson, Lettau e Steindel (2002) deram contribuição importante à compreensão desta afirmação
} 
rios pode capturar indevidamente a influência de variáveis correlacionadas, como a inflação, sobre o estoque real de riqueza ${ }^{18}$. Evidências para a economia americana corroboram as objeções levantadas. Para o caso do Brasil, embora não haja evidência bem estabelecida, é de esperar um efeito riqueza ainda menor do que nos EUA, dado que o estoque de riqueza como proporção do PIB é muito maior na economia americana, bem como sua distribuição menos concentrada. Além disso, boa parte da potência do efeito riqueza nos EUA resulta de um elemento ausente em economias com mercados de renda variável menos desenvolvido como o Brasil ${ }^{19}$. Em suma, dada a irrelevância do canal em si, esta obstrução não deveria ser fonte de maiores preocupações para a economia brasileira.

Vale frisar, contudo, que embora os movimentos da taxa de juros costumem ser temporários, retornando tão logo ao seu patamar de neutralidade, no caso brasileiro percebe-se claramente uma mudança de patamar no nível da taxa de juros ao longo do tempo. Nesse sentido, as mudanças induzidas pela política monetária podem ter tido efeitos permanentes na riqueza dos agentes, afetando seu consumo e devendo afetá-lo enquanto perdurar esta longa travessia da economia brasileira rumo à normalidade.

Além disso, vale citar a contribuição abaixo de Pastore (2006, p. 263), sobre a possível importância das LFTs e do canal do efeito riqueza no Brasil:

$\mathrm{Na}$ literatura internacional, há muitas referências à operação do efeito riqueza, mas isso ocorre em parte porque as taxas de juros nos países industrializados são baixas e têm pouca volatilidade, e em parte porque a dívida pública nesses países é uma proporção pequena do estoque total de riqueza (representada predominantemente por ações e imóveis). Assim, ao operar por intermédio da dívida pública, a ação do efeito riqueza é pequena, sendo praticamente ignorada. No caso brasileiro, as variações da taxa de juros real são muito grandes e a proporção da dívida pública

ao mostrar que a demanda por consumo dos agentes responde de forma desigual a variações do estoque de riqueza dos consumidores, caso estas sejam consideradas transitórias ou permanentes. Mudanças transitórias, ao contrário das permanentes, provocam uma resposta tênue da demanda por consumo.

${ }^{18}$ Suponha, por exemplo, uma elevação de preços de commodities que aumente a inflação. Parte do efeito riqueza aparentemente associado com a elevação do juro resultaria, na verdade, da queda do valor real dos ativos causado pela corrosão inflacionária ou pela contração derivada de choques de oferta adversos.

${ }^{19}$ Segundo Loyo (2006, p. 304), “resultado de Bernanke e Kuttner (2005) sugere que o principal impacto de um aperto monetário para a queda das ações no mercado acionário não é, surpreendentemente, elevar a taxa de desconto livre de risco, nem deprimir o fluxo de dividendos, mas sim aumentar o prêmio de risco dos ativos de renda variável (equity premium). As razões disso estariam ligadas à maior incerteza econômica despertada pela necessidade de um aperto monetário, fator que reduziria o apetite dos investidores para enfrentar riscos e tornaria os próprios retornos no mercado acionário mais incertos, contribuindo para o aumento dos prêmios. Esses efeitos sobre o equity premium, por definição, não se aplicam a ativos de renda fixa". Isto posto, importante colocar que os ativos de renda fixa, em particular, dívida do governo, respondem por uma proporção maior da riqueza financeira no Brasil. 
em relação ao PIB, alta. Consequentemente, esse efeito poderia ser, em princípio, de grande magnitude, não fosse o fato de que a dívida pública tem uma elevada proporção de LFTs.

\section{Truncada estrutura a termo da taxa de juros}

A truncada estrutura a termo da taxa de juros brasileira constitui um entrave à transmissão da política monetária pelo canal das taxas de juros no país. De acordo com Cardim de Carvalho (2005; p. 331):

[...] três décadas de alta inflação tornaram impossível a constituição de uma curva de rendimentos que se estendesse para além do curto prazo. A estabilidade de preços alcançada com o Plano Real, por outro lado, não permitiu que se construísse uma situação de normalidade financeira já que ela foi conseguida em um ambiente definido pela existência de um mercado financeiro dominado por papéis públicos de curta maturidade efetiva, remunerados por taxas de juros excepcionalmente elevadas.

Nesse contexto, “os estímulos gerados pela política monetária não se transmitiriam para os segmentos mais longos, onde pudessem influenciar as escolhas de investimento real, pela inexistência daqueles segmentos" (Ibidem, p. 332). Ou seja, uma obstrução no canal das taxas de juros:

\section{$\uparrow i \rightarrow \uparrow i^{\prime}$ longas $^{\rightarrow} \downarrow I \rightarrow \downarrow Y \rightarrow \downarrow \pi$ \\ $\longrightarrow$ Obstrução nesta transmissão}

Soma-se a isso o fato que títulos emitidos com taxas de juros fixas e prazos de vencimento mais longos produzem um efeito-riqueza maior do que títulos emitidos com prazos de vencimento mais curtos. Para o caso da economia brasileira, dada à inexistência de segmentos mais longos, não existe efeito-riqueza operando nestas faixas da curva de rendimentos em que há maior potencial de geração do mesmo:

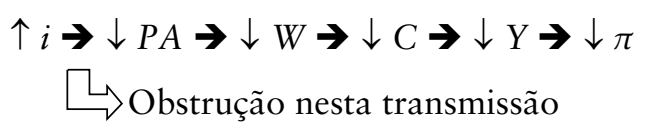

Participação de preços administrados no índice oficial de inflação

A elevada participação de preços administrados no IPCA (índice de referência para a o regime de metas de inflação no país), que monta a cerca de $25 \%$ deste índice, reduz a eficácia da transmissão da política monetária à taxa de inflação na economia brasileira - veja, dentre outros, Figueiredo e Ferreira (2002), Sicsú e Oliveira (2003), Aidar (2006), Bacha (2010), Serrano e Summa (2011) e Modenesi e Modenesi (2012).

Preços administrados é o nome genérico que recebem os preços que são auto- 
rizados pelo governo (em quaisquer das suas três esferas) ou reajustados segundo regras contratuais fixas de indexação:

Os autorizados são, por exemplo, o valor das tarifas de transporte de ônibus nos municípios, que depende de autorização dos prefeitos; ou o valor das tarifas de transporte de ônibus intermunicipais que depende de autorização dos governadores. Os administrados podem, portanto, ser divididos em autorizados e indexados. A indexação com base no IGP é a mais comum das regras - por exemplo, são preços indexados por contrato, os preços da energia elétrica e da telefonia. (Sicsú e Oliveira, 2003, p. 59)

Como preços administrados são insensíveis às condições de oferta e demanda porque são estabelecidos por contrato ou por órgão público, eles não se alteram perante mudanças na política monetária. Desse modo, cerca de $25 \%$ da taxa oficial de inflação tem sua dinâmica determinada a despeito de alterações na taxa de juros. A consequência deste panorama, segundo Bacha (2010, p. 18), "é que um aperto monetário tem que ser mais forte e mais duradouro do que seria o caso se houvesse maior flexibilidade dos preços administrados".

Trata-se, portanto, de uma característica da economia brasileira que reduz a capacidade da política monetária de alterar a taxa de inflação no país, pois sempre que um impulso monetário se aproxima da taxa de inflação, ele encontra um obstáculo (preços administrados) que o impede de alcançar com maior força seu destino final. Dito de outra forma, a existência de preços administrados reduz a sensibilidade da taxa de inflação diante do que ocorre com a demanda (ou o hiato do produto) no Brasil ${ }^{20}$ :

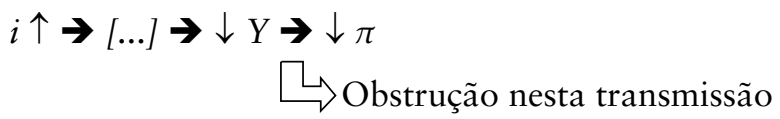

Esta obstrução, contudo, era acentuada na economia brasileira entre 2000 e 2007, quando a inflação de administrados rodava bem acima da inflação de preços livres. Em um trabalho que remonta a um subperíodo desta época, Figueiredo e Ferreira (2002) colocam que "a política monetária poderia ter sido consideravelmente mais amena caso os preços administrados apresentassem um comportamento semelhante ao dos preços livres". A partir de 2007, entretanto, o cenário muda e o preço relativo dos administrados diminui em relação aos preços livres. Desse modo, a obstrução supracitada, na verdade, acaba se tornando um colaborador da política monetária, retirando pressão do $\mathrm{BCB}$ ao demandar menores doses de taxa de juros para a perseguição da meta de inflação ${ }^{21}$.

\footnotetext{
${ }^{20}$ Para evidências empíricas da influência dos administrados na política monetária, ver Aidar (2006).

${ }^{21}$ Este auxílio dos preços administrados pode ter sido um fator a contribuir positivamente para a queda observada na taxa de juros no pós-2007. Porém, é importante diferenciar dois movimentos: (i) preços administrados aumentando naturalmente menos do que preços livres; (ii) preços administrados sendo
} 


\section{MECANISMOS DE TRANSMISSÃO E TAXA DE JUROS NO BRASIL}

Esta seção desenvolve, sob ponto de vista teórico, a hipótese de que mecanismos de transmissão parcialmente obstruídos acarretam consequências perversas para a política monetária praticada no Brasil. Tais consequências seriam: (i) elevação da volatilidade da taxa de juros; (ii) elevação do nível da taxa de juros.

Para considerar a relação entre obstruções de transmissão e volatilidade da taxa de juros, é necessário perceber que, na presença daquelas, sempre tende a ser maior a resposta da política monetária em face de choques exógenos na economia. Por exemplo, no caso de um choque de demanda positivo, a autoridade monetária precisará elevar mais fortemente a taxa de juros na presença de obstruções de transmissão do que na ausência delas. O contrário ocorre no caso de um choque de demanda negativo.

Para avaliar a relação entre obstruções e nivel de taxa de juros, é preciso, antes de tudo, aceitar a hipótese de que, tudo o mais constante, o nível da taxa de juros guarda relação com o nivel da demanda agregada. Assim, se os canais que transmitem a taxa de juros para as decisões de gasto são menos efetivos do que poderiam ser, então o nível da taxa de juros requerido para assegurar determinado nível de demanda acaba sendo mais alto nesse caso do que no caso de não haver obstruções nos mecanismos de transmissão. Ou seja, obstruções demandam a todo o momento do banco central um maior nivel de taxa de juros para a manutenção de determinado nível de demanda agregada.

Para esclarecer o raciocínio, vamos recorrer ao uso de um modelo macro de três equações, o modelo BMW, que contém uma Curva IS, uma Curva de Philips e uma Função de Perda do Banco Central - Bofinger, Mayer e Wollmershauser (2006):

(1) Curva IS: $y=a-b r+\varepsilon_{D}$

(2) Curva de Philips: $\pi=\pi^{M}+d y+\varepsilon_{O}$

(3) Regra de PM: $L=\left(\pi-\pi^{M}\right)^{2}+\lambda y^{2}$

Nas equações acima, $y$ representa o hiato do produto, $\varepsilon_{D}$ choques de demanda, $\pi$ a taxa de inflação, $\pi^{M}$ a meta de inflação, $\varepsilon_{O}$ choques de oferta e $L$ a função de perda do banco central. Supõe-se um regime de metas de inflação não restrito $(\lambda>0)$, com um banco central de credibilidade perfeita (o que justifica $\pi^{M}$ como inflação esperada) e que consegue controlar a taxa real de juros (embora controle mesmo a taxa nominal).

\footnotetext{
represados por vontade política. Este segundo (que aparenta ter ocorrido mais recentemente na economia brasileira) pode auxiliar no combate à inflação no curto prazo, mas depois prejudicar, dado que os agentes passam a esperar uma elevação daqueles preços, criando uma rigidez nas expectativas de inflação. Assim, é possível que o controle político de preços administrados acabe demandando maiores (e não menores) doses de taxa de juros para manutenção da estabilidade de preços.
} 
O parâmetro $b$ - protagonista da inclinação da Curva IS - representa a derivada parcial do hiato do produto em relação à taxa de juros ( $\partial \mathrm{Y} / \partial \mathrm{r})$, que significa o "quanto varia o hiato do produto mediante uma variação da taxa de juros". Na presença de obstruções nos mecanismos de transmissão, menor deve ser o valor de $\mathrm{b}^{22}$.

De maneira geral, o que se está propondo é que o valor de b é sensível ao grau de obstrução dos mecanismos de transmissão da política monetária. Tudo o mais constante, quanto mais obstruções houver nos mecanismos de transmissão monetária, menor será o valor de b e mais inclinada será a curva IS. Por sua vez, quanto mais inclinada a IS, maior será o nível requerido de taxa de juros para manutenção da demanda agregada no nível do produto potencial $(y=0)$. Vejamos esta proposição pela resolução do modelo.

Inserindo a equação (2) em (3), obtém-se uma função de perda do banco central modificada:

(4) $L=d^{2} y^{2}+2 d y \varepsilon_{O}+\varepsilon_{O}^{2}+\lambda y^{2}$

Minimizando a função de perda do banco central modificada, e resolvendo para o hiato do produto, tem-se:

(5) $y=-\frac{d}{d^{2}+\lambda} \cdot \varepsilon_{O}$

Inserindo (5) em (1) e resolvendo para a taxa real de juros, obtém-se a taxa real de juros ótima do modelo, isto é:

$$
r^{\text {ótima }}=\frac{a}{b}+\frac{1}{b} \varepsilon_{D}+\frac{d}{b\left(d^{2}+\lambda\right)} \varepsilon_{O}
$$

Como o parâmetro b se encontra no denominador da taxa ótima de juros, quanto menor o seu valor - dito de outra forma, quanto mais obstruídos forem os mecanismos de transmissão monetária -, mais elevada será a taxa de juros da economia sob análise. A rigor, este mesmo resultado poderia ter sido encontrado pelo simples exame da curva IS, para o caso em que o hiato do produto é zero $(y=0)$ e supondo a inexistência de choques na economia $\left(\varepsilon_{D}=\varepsilon_{O}=0\right)$. A expressão (7) abaixo ilustra esta argumentação:

\footnotetext{
${ }^{22} \mathrm{O}$ parâmetro b pode ser visto como: $\mathrm{b}=\mathrm{f}$ (obstruções de transmissão), tal que $\mathrm{f}^{\prime}<0$. Vale sublinhar que este trabalho lida com uma IS obtida sem qualquer apelo à microfundamentação. Esta ressalva é relevante, pois o parâmetro $b$ possui significado diferente quando derivado de um modelo microfundamentado como, por exemplo, ocorre na literatura novo-keynesiana. Sobre essa literatura, ver Galí (2008). Para uma análise crítica da necessidade de microfundamentação da macroeconomia ver, dentre outros, Lichand, Gala e Jardim (2009) e King (2008). Ademais, vale notar que o parâmetro b capta a influência de todas as falhas de transmissão expostas neste artigo, com exceção da participação dos administrados no IPCA.
} 
(7) $r^{\text {ótima }}=\frac{a}{b}$

Em síntese, tanto em (6) quanto em (7) pode-se visualizar que a existência de obstruções nos mecanismos de transmissão da política monetária implica na necessidade de uma taxa de juros "de equilíbrio" mais elevada para a condução da politica monetária.

\section{EVIDÊNCIAS PRELIMINARES}

Algumas evidências preliminares estão em linha com a hipótese desenvolvida por este trabalho. Vejamos.

Grafico 3: Taxa Selic e Paticipação do Crédito Direcionado no Créditototal

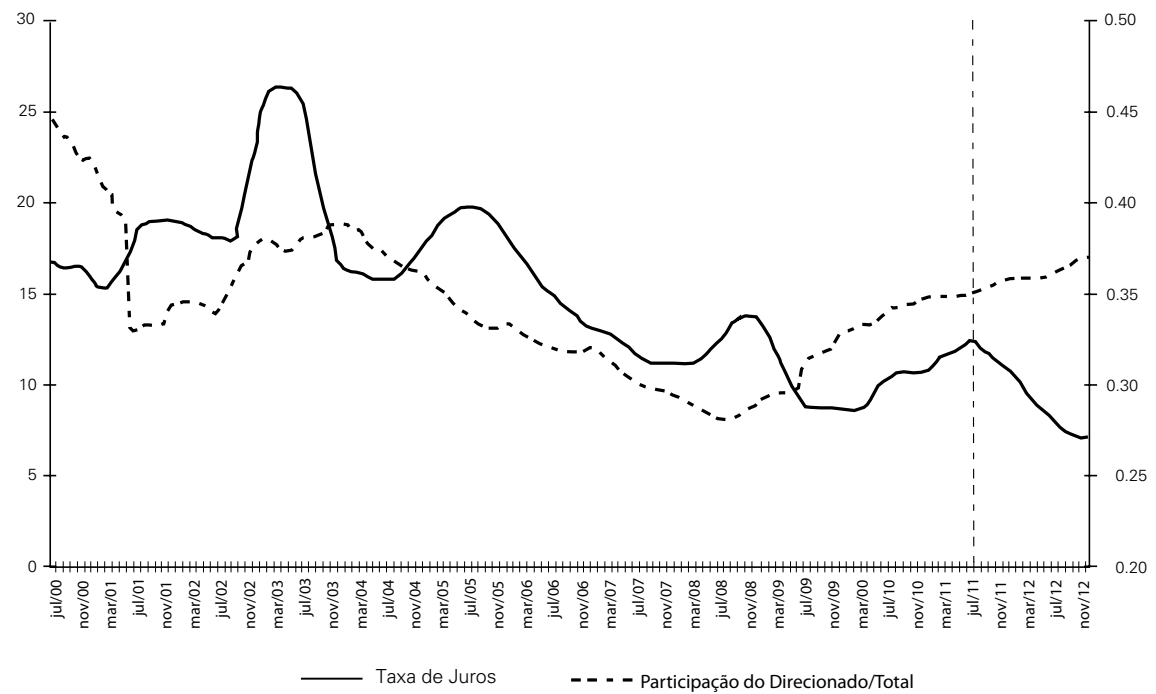

O Gráfico 3 mostra as trajetórias da taxa de juros e da participação do crédito direcionado no crédito total no Brasil ${ }^{23}$. Nota-se uma correlação positiva entre as duas variáveis. No fim do gráfico, contudo, ocorre um descolamento entre as duas séries, que coincide com a polêmica reunião do Copom de agosto de 2011, quando o Banco Central reduziu a taxa de juros a despeito das previsões de grande parte dos analistas econômicos. Tal movimento, aparentemente não respaldado pela desobstrução do canal do crédito que, conforme visto, pode ter influência sobre a taxa de juros de "equilíbrio", acabou se mostrando inflacionário e o BCB foi obrigado a elevar novamente a taxa de juros a partir de 2013.

\footnotetext{
${ }^{23}$ O gráfico se encerra em dezembro de 2012, pois esta série histórica parou de ser alimentada pelo BCB. Uma nova série foi criada, mas possui início apenas em 2007.
} 


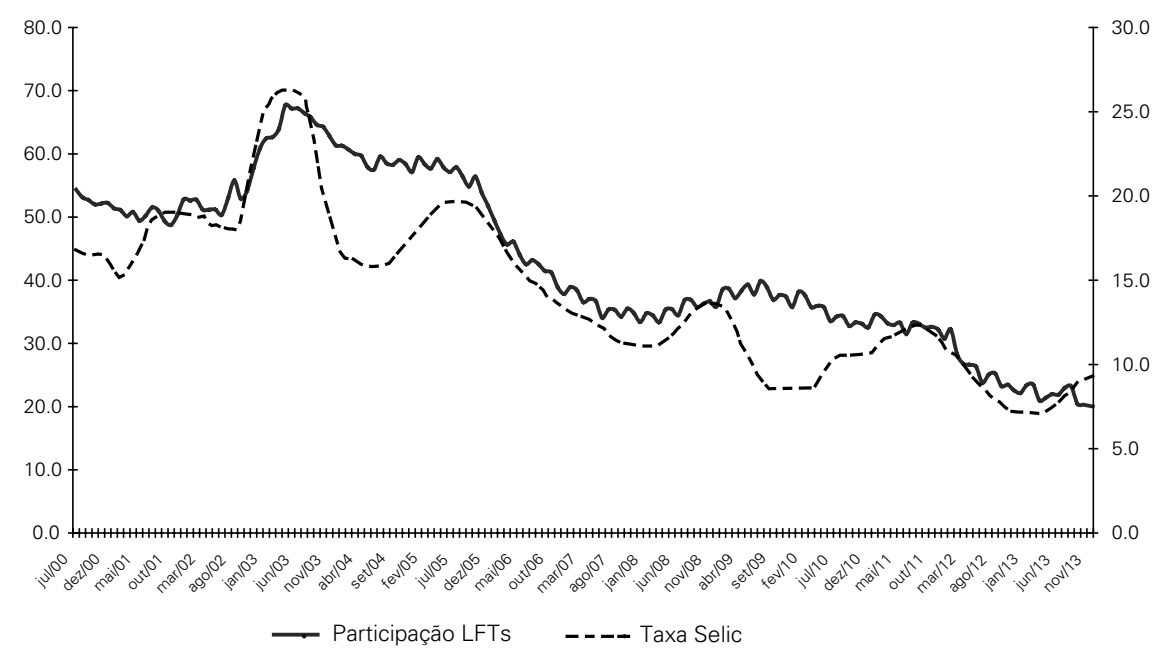

O Gráfico 4, por sua vez, compara as evoluções da taxa de juros e da participação das LFTs na composição da dívida pública no Brasil. Mais uma vez, observase uma correlação positiva entre as séries. A queda da taxa de juros tem ocorrido tendencialmente lado a lado com a cada vez menor participação de LFTs na composição da dívida pública.

Uma ressalva fundamental: correlação não implica causalidade. Sem evidências mais rigorosas, não há como provar as relações aqui propostas. Isto por dois motivos: (i) tanto uma redução de participação do crédito direcionado no crédito total eleva o poder da política monetária e possibilita uma queda não inflacionária da taxa de juros quanto uma queda da taxa de juros estimula o crédito livre e reduz o peso do direcionado no crédito total; (ii) tanto uma menor participação de LFTs eleva a potência monetária e viabiliza uma queda no juro, quanto a expectativa de queda do juro reduz a demanda por LFTs. Assim sendo, faz-se necessário um maior controle sobre tais variáveis a fim de identificar a causalidade correta (ou até mesmo se as relações apresentadas são espúrias).

Isto posto, podemos apresentar outras evidências, estas sim mais embasadas, que aparentemente vão na direção proposta pela hipótese aqui desenvolvida.

Um estudo do BCB, denominado "Poder da Política Monetária no Brasil", publicado no Boxe do Relatório de Inflação de junho de 2010 afirma que o poder da política monetária tem aumentado na economia brasileira. O conceito de poder da política monetária diz respeito à sensibilidade da taxa de inflação à taxa de juros, passando pelo hiato do produto. Uma forma de mensurar tal variável ocorre através do produto da soma dos coeficientes da taxa de juros na curva IS pela soma dos coeficientes do hiato do produto na curva de Philips. De acordo com os coeficientes estimados pelos modelos estruturais de pequeno porte do $\mathrm{BCB}$, encontra-se evidência de ampliação do poder da política monetária no Brasil e as supostas causas desse processo, nas palavras do próprio BCB (2010, p.102), seriam a 
“[...] expansão do crédito em relação ao Produto Interno Bruto (PIB), bem como de sua maturação; menor concentração da dívida pública em títulos atrelados à taxa Selic; e aumento do prazo médio dos títulos da divida pública”. Ou seja, justamente as obstruções de transmissão.

Costa Neto (2007) também mostra evidência de ampliação do poder da política monetária no Brasil. Seus resultados sugerem que o desenvolvimento financeiro de um país influencia positivamente no poder da política monetária, com um aumento de 10 p.p. no crédito privado total/PIB de um país provocando contração de 0,068 p.p. da resposta da variação da inflação ao choque de juros no mesmo país. Como no Brasil a relação crédito livre/PIB aumentou de $15 \%$ para $30 \%$ entre 2003 e 2013, isto significa um maior aprofundamento do crédito na renda e um consequente aumento do poder da política monetária, o que deve demandar menores doses de taxa de juros para o BCB manter a taxa de inflação na meta.

Alguns artigos se dedicam a comparar o poder da política monetária entre Brasil e países onde as obstruções de transmissão monetária não ocorrem. Matsumoto (2000), por exemplo, compara Brasil e Argentina. Seus resultados mostram o seguinte:

Distinção maior restringe-se à esfera quantitativa, onde se nota um grau maior de sensibilidade à transmissão de política monetária na economia argentina, na qual um impulso monetário de igual intensidade relativa é capaz de produzir efeitos reais cerca de três vezes superior do que na brasileira, tanto no produto como nos preços. (Ibidem, p. 48)

Em que pese o período em que foi realizada a pesquisa (décadas de 1980 e 1990), e também o fato da economia argentina ter tido, à época, maior tempo de estabilidade que a economia brasileira (o que influencia na transmissão monetária — ver Lopes, 1997), tal resultado mostra grande diferença de poder da política monetária entre os dois países.

Lopes (2011, p. 124), por sua vez, compara o poder da política monetária entre Brasil e Estados Unidos (EUA). Nas palavras do autor:

Se simulamos uma elevação de 5 pontos percentuais na taxa do banco central (na taxa dos FED funds nos EUA e na taxa Selic no Brasil), obtemos uma perda de produto industrial acumulada em 3 anos da ordem de 16 pontos percentuais nos EUA e de 4 pontos percentuais para o Brasil, em relação à uma trajetória original de referência. Ou seja, a sensibilidade do nível de atividade à taxa de juros parece ser quatro vezes menor no nosso caso. O impacto acumulado ao longo de 3 anos sobre a taxa de inflação dos preços ao consumidor seria uma redução de 3,4 pts \% nos EUA e de 0,8 pts\% no Brasil, novamente uma diferença por um fator multiplicativo da ordem de 4.

Em suma, algumas evidências preliminares mostram ser baixo o poder da política monetária no Brasil e que este cenário pode ter como causa as obstruções 
existentes nos mecanismos de transmissão da política monetária. Evidência adicional, contudo, faz-se necessária. Esta seção deve, pois, ser encarada como uma abordagem preliminar que, pela relevância do tema, necessita de maior refinamento e abordagens alternativas.

\section{CONSIDERAÇÕES FINAIS}

Duas décadas após o lançamento do Plano Real, a estabilização brasileira continua incompleta. A taxa de juros no Brasil não só é a maior do planeta, mas situa-se acima de qualquer padrão internacional. Segundo Sabóia (2005), a economia brasileira possui "a rainha das taxas de juros".

Para explicar este problema, o artigo desenvolveu a hipótese, um tanto quanto fragmentada na literatura, de que a alta taxa de juros se deve, pelo menos em parte, à existência de mecanismos de transmissão da política monetária parcialmente obstruídos. As obstruções de transmissão não são poucas e se mostram presentes, em graus diferentes, em vários dos principais canais que conectam taxa de juros e taxa de inflação no país (respectivamente, instrumento e objetivo da política monetária). Este artigo consolidou as diversas contribuições e esquematizou suas influências no juro através de um modelo macroeconômico básico de três equações (modelo BMW).

De fato, a segmentação do mercado de crédito, a baixa importância do crédito livre na determinação da demanda agregada, a truncada estrutura a termo da taxa de juros e a participação de LFTs na composição da dívida pública, todas juntas, elevam a inclinação da curva IS na economia brasileira e exigem um maior nível de taxa de juros do banco central para que este possa minimamente cumprir com seu objetivo de manter a inflação na meta, com a economia operando ao nível do produto potencial.

Embora algumas evidências preliminares tenham sido apresentadas, o argumento ainda carece de base empírica mais rigorosa. Caso comprovada a hipótese, reduções permanentes - e não inflacionárias — da taxa de juros poderiam ocorrer mediante políticas que atuem na desobstrução dos mecanismos de transmissão da política monetária. Sem isso, é possível que tentativas menos abalizadas para sua redução acabem gerando como resultado tão somente mais inflação.

\section{REFERÊNCIAS BIBLIOGRÁFICAS}

AIDAR, O. A. B. (2006) “Os Preços Administrados e a Condução de Política Monetária no Brasil”. Dissertação de Mestrado. EESP-FGV.

ANDRADE, J. P.; CASTRO PIRES, M. C. (2009) “A transmissão da política monetária pelo canal do efeito riqueza no Brasil”. In: Política monetária, Bancos Centrais e Metas de Inflação. Orgs: Oreiro, Paula e Sobreira: FGV Editora, pp. 209-235.

ARIDA, P. BACHA, E. e RESENDE, A. L. (2005) “Credit, Interest and Jurisdictional Uncertainty: Conjectures on the Case of Brazil”. In: F. Giavazzi, I. Goldfajn e S. Herrera (orgs.). Inflation Targeting, Debt, and the Brazilian Experience. MIT Press. 
ARIDA, P. (2003a) “Múltiplos equilíbrios”. Revista de Economia Política, v. 22, n. 3, pp. 122-31, jul./ set.

ARIDA, P. (2003b) "Por uma moeda plenamente conversível”. Revista de Economia Política, v. 23 (3), pp. 135-142.

BACHA, E. (2011) “Além da Tríade: Como Reduzir os Juros?” In: Novos dilemas de política econômica: Ensaios em homenagem a Dionísio Dias Carneio. Orgs: E. Bacha e M. de Bolle: LTC.

BALL, L. (1992) "Desinflation with Imperfect Credibility". Journal of Monetary Economics, 35(1), p. 5-23.

BANCO CENTRAL DO BRASIL. (2010) “O Poder da Política Monetária no Brasil”. Boxe do Relatório de Inflação, Junho de 2010.

BARBOSA, F. H. (2006) "The Contagion Effect of Public Debt on Monetary Policy: the Brazilian Experience”. Revista de Economia Política, v. 26, n 2, pp. 231-238.

BARROS, O. de. (2011) “A Taxa de Impaciência do Brasileiro é mais Alta do que em Outros Países?”. Publicação Bimestral Bradesco. Ed. ${ }^{\circ}$ 34. Junho.

BAUMOL, W. J. (2012) “The Cost Disease: Why Computers Get Cheaper and Health Care Doesn't”. Yale University Press.

BERNANKE, B; GERTLER, M. (1995) "Inside the black box: the credit channel of monetary policy transmission". The Journal of Economic Perspectives, v. 9, p. 27-48.

BOFINGER, P.; MAYER, E.; WOLLMERSHAUSER, T. (2006) "The BMW Model: A New Framework for Teaching Monetary Economics". Journal of Economic Education.

BOGDANSKI, J.; TOMBINI, A.; WERLANG, S. R.; (2000) "Implementing inflation target in Brazil". Brasília, DF: Working Paper $n^{\circ} 1, B C B$.

BOMFIM, A.; TETLOW, R. MUEHLEN, P.; WILLIAMS, J. (1997) "Expectations, Learning and the Costs of Desinflation: Experiments Using the FRB/US Model”. Federal Reserve Board Finance and Economics Discussion Series $n^{\circ} 42$.

BRESSER-PEREIRA, L. C; NAKANO, Y. (2002) "Uma Estratégia de Desenvolvimento com Estabilidade". Revista de Economia Política, v. 22, n. 3, pp. 146-180, jul./set.

CARDIM DE CARVALHO, F. J. (2005) "Uma contribuição ao debate em torno da eficácia da política monetária e algumas implicações para o caso do Brasil”. Revista de Economia Política, vol. 25, n. 4; outubro-dezembro.

CARDIM DE CARVALHO, F. J.; PIRES de SOUZA, F. E; SICSU, J. STUDART, PAULA, L. F. (2007). Economia Monetária e Financeira. Editora Campus, $2^{a}$ Edição.

COSTA NETO, N. C. (2007) "Desenvolvimento Financeiro e Potência da Política Monetária: uma abordagem cross country". Dissertação de Mestrado, PUC-RJ.

ERBER, F. (2008) "Development projects and growth under finance domination - the case of Brazil during the Lula years (2003-2007)". Revue Tiers Monde, 194.

FAVERO, C.; GIAVAZZI, F. (2002) “Why are Brazil's Interest Rates so High?” Innocencio Gasparini Institute for Economic Research, Working Paper No. 224.

FIGUEIREDO, F. M. R.; FERREIRA, T. P. (2002) "Os Preços Administrados e a Inflação no Brasil". Working Paper ${ }^{\circ} 59$, BCB.

FRANCO, G. (2006) “Notas Sobre Crowding Out, Juros Altos e Letras Financeiras do Tesouro”. In: Mercado de capitais e dívida pública: tributação, indexação e alongamento; Orgs.: E. Bacha e Oliveira Filho; Contra Capa Livraria.

GONÇALVES, F; HOLLAND, M; SPACOV, A. (2007) "Can jurisdictional uncertainty and capital controls explain the high level of real interest rate in Brasil? A Panel Analysis". Revista Brasileira de Economia, v. 61, $\mathrm{n}^{\circ} 1$.

KING, J. (2009) “Microfoundations?”. In: Macroeconomic Policy on Shaky Foundations: Whither Mainstream Economics? Edited by E. Hein, T. Niechoj, E. Stockhammer. Metropolis Verlag. Marburg.

LICHAND, G.; GALA, P.; JARDIM, E. F. (2009) “Microfundamentos da Macroeconomia: Notas Críticas". Estudos Econômicos, v. 39, n 4.

LOPES, F. (1997). "O mecanismo de transmissão de política monetária numa economia em processo de estabilização: notas sobre o caso do Brasil". Revista de Economia Política, volume 17, n 3 .

LOPES, F. (2011) “A Estabilização Incompleta”. In: Novos dilemas de política econômica: Ensaios em homenagem a Dionísio Dias Carneio. Orgs: Bacha e de Bolle; Rio de Janeiro: LTC. 
LOYO, E. (2006) “Política Monetária e Alongamento da Dívida Pública”. In: Mercado de capitais e dívida pública: tributação, indexação e alongamento; Orgs.: E. Bacha e L. C. Oliveira Filho; Contra Capa Livraria.

LUDVIGSON, S.; STEINDEL, C.; LETTAU, M. 2002 "Monetary policy transmission through the consumption-wealth channel”. Federal Reserve Bank of New York Economic Policy Review, May: $117-133$.

LUNDBERG, E. L. (2011) “Bancos Oficiais e Crédito Direcionado - O que diferencia o mercado de crédito brasileiro?” Trabalhos para Discussão n ${ }^{\circ} 258$, BCB.

MATSUMOTO, K. (2000) "Efeitos Reais da Transmissão de Política Monetária: comparação empírica entre Brasil e Argentina". Dissertação de mestrado, EPGE-FGV.

MENDONÇA, H. F. (2001) "Mecanismos de Transmissão Monetária e a Determinação da Taxa de Juros: uma aplicação da Regra de Taylor ao caso brasileiro”. Economia e Sociedade, (16), 65-81, jun.

MESQUITA, M. (2014) "Esquenta o debate”. Jornal Valor Econômico, 16/01/2014.

MINELLA, A.; SOUZA-SOBRINHO, N. F. (2011) "Canais Monetários no Brasil Sob a Ótica de um Modelo Semiestrutural”. In: BCB, Dez Anos de Metas Para Inflação 1999-2009, BCB.

MISHKIN, F. S. (1995) "Symposium on the monetary transmission mechanism". The Journal of Economic Perspectives, v. 9, n. 4, p. 1-10.

MODENESI, A.; MODENESI, R. L. (2012) “Quinze Anos de Rigidez Monetária no Brasil Pós-Plano Real: uma agenda de pesquisa”. Revista de Economia Política, v. 32, n 3 (128), pp. 389-411.

MUINHOS, M. K; NAKANE, M. (2006) “Comparing Equilibrium Real Interest Rates: Different Approaches to Measure Brazilian Rates”. BCB Working Paper No. 101.

ONO, F. H; OREIRO, J. L; PAULA, L. F. R de; SIVA, G. J. (2005) "Conversibilidade da conta de capital, taxa de juros e crescimento econômico: uma avaliação empírica da proposta de plena conversibilidade do real". Revista de Economia Contemporânea. V. 9.

OREIRO, J. L; AMARAL, R. Q. (2008) "Relação Entre o Mercado de Dívida Pública e a Política Monetária no Brasil". Revista de Economia Contemporânea, v. 13.

OREIRO, J. L; PAULA, L. F. (2011) “A Escolha de Sofia”. Jornal Valor Econômico, 24/06/2011.

PASTORE, A. C. (1996) "Porque a Política Monetária Perde Eficácia?” Revista Brasileira de Economia, v. 50, p. 281-311.

PASTORE, A. C. (2006) “As Letras Financeiras do Tesouro e a Eficácia da Política Monetária”. In: Mercado de capitais e dívida pública: tributação, indexação e alongamento; Orgs.: E. Bacha e L. C. Oliveira Filho; Contra Capa Livraria.

RESENDE, A. L. (2011) “Juros: Equívoco ou Jabuticaba?”. Jornal Valor Econômico, 16/06/2011.

ROBERTS, J. (2006) “Monetary Policy and Inflation Dynamics”. International Journal of Central Banking, 2, p. 193-230.

SABOIA, J. (2005) “A Rainha das Taxas de Juros”. Jornal Valor Econômico, 10/01.

SANT'ANNA, A. A.; BORÇA JUNIOR, G. R.; QUARESMA de ARAUJO, P. (2009) "Mercado de Credito no Brasil: Evolução Recente e o Papel do BNDES (2004-2008)". In: Ensaios sobre Economia Financeira: Orgs: ROCHA FERREIRA, F. M.; BARBOSA MEIRELLES, B. — Rio de Janeiro: BNDES.

SCHWARTSMAN, A. (2011) "Sobre Jabutis e Jabuticabas". Jornal Valor Econômico, 07/07/2011.

SEGURA-UBIERGO, A. (2012) “The Puzzle of Brazil's High Interest Rates”. IMF Working paper 12/62. IMF. February.

SERRANO, F.; SUMMA, R. (2011) "Política Macroeconômica, Crescimento e Distribuição de Renda na Economia Brasileira dos anos 2000". CECON-UNICAMP.

SICSÚ, J.; OLIVEIRA, S. C. (2003) “Taxa de juros e controle da Inflação no Brasil”. In: Agenda Brasil: políticas econômicas para o crescimento com estabilidade de preços. Orgs: J. Sicsú, J. L. Oreiro e L. F. de Paula. Editora Manole.

TAYLOR, J. B. (1995) “The Monetary Transmission Mechanism: An Empirical Framework”; Journal of Economic Perspectives - Volume 9, Number 4.

TOBIN, J. (2003) "World Finance and Economic Stability". Selected Essays of James Tobin. Cheltenham: Edward Elgar. 